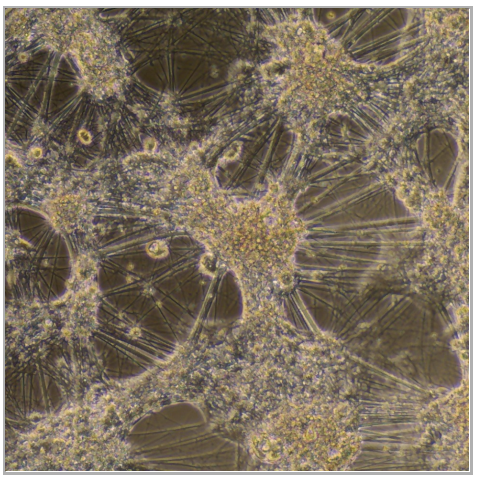

JUL 23, 2020

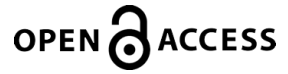

DOI:

dx.doi.org/10.17504/protocol s.io.bh32j8qe

Protocol Citation: Julie Jerber, James Haldane, Juliette Steer, Daniel Pearce, Minal Patel 2020. Dissociation of neuronal culture to single cells for scRNA-seq ( $10 \mathrm{x}$ Genomics) . protocols.io https://dx.doi.org/10.17504/p rotocols.io.bh32j8qe

License: This is an open access protocol distributed under the terms of the Creative Commons Attribution License, which permits unrestricted use, distribution, and reproduction in any medium, provided the original author and source are credited

Protocol status: Working We use this protocol and it's working

Created: Jun 30, 2020

Last Modified: Jul 24, 2020

PROTOCOL integer ID: 38746

\section{(3) Dissociation of neuronal culture to single cells for scRNA-seq (10x Genomics)}

Julie Jerber ${ }^{1}, \quad$ James Haldane ${ }^{2}$, Juliette Steer ${ }^{1}$, Daniel Pearce $^{1}$, Minal Patel ${ }^{1}$

${ }^{1}$ Wellcome Sanger Institute; ${ }^{2}$ bit. bio

Cellular Generation and Phenotyping

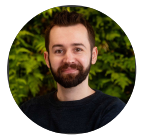

James Haldane

bit. bio

\section{ABSTRACT}

This protocol outlines a method for dissociating a human pluripotent stem cellderived neuronal culture to single cells for loading onto a Chromium 10x chip for single cell RNA-sequencing.

This protocol makes a distinction between early neuronal progenitors and mature neuronal cultures, as additional steps and reagents are required in order to sufficiently dissociate the latter. These include:

- DNase Vial (D2)

\section{- PDS Kit Papain Vial}

Note: In our labs, iPS cells were undergoing a 52-day long differentiation process to dopaminergic neurons (adapted from doi.org/10.1038/nature10648), and were treated under the 'mature' conditions when harvested from day 20 onward, and as 'early neuronal progenitors' on day 11. Example images of neuronal culture from our labs can be found in the Guidelines of this protocol for reference.

This protocol assumes use of:

- 12-well tissue culture plates ( $3.8 \mathrm{~cm}^{2}$ surface area per well ) for samples/wells being harvested for dissociation (see Materials).

- A NucleoCounter ${ }^{\circledR} \mathrm{NC}-200^{\mathrm{TM}}$ for purposes of cell counting.

\section{GUIDELINES}

Unless otherwise stated, all steps should be performed under sterile conditions in a CL2 biological safety cabinet.

Refer to 10x Genomics Chromium single cell gene expression kit guidelines for subsequent steps in loading cells. 
Keywords: neuronal, dissociation, 10x, single-cell, cell-culture, scRNA-seq, neurons
Below are example images showing a neuronal culture undergoing a 52-day differentiation to dopaminergic neurons. These are for reference regarding dissociation steps in this protocol that differ for early neuronal progenitors and mature neurons. Details on the protocol used can be found in the Abstract of this protocol.

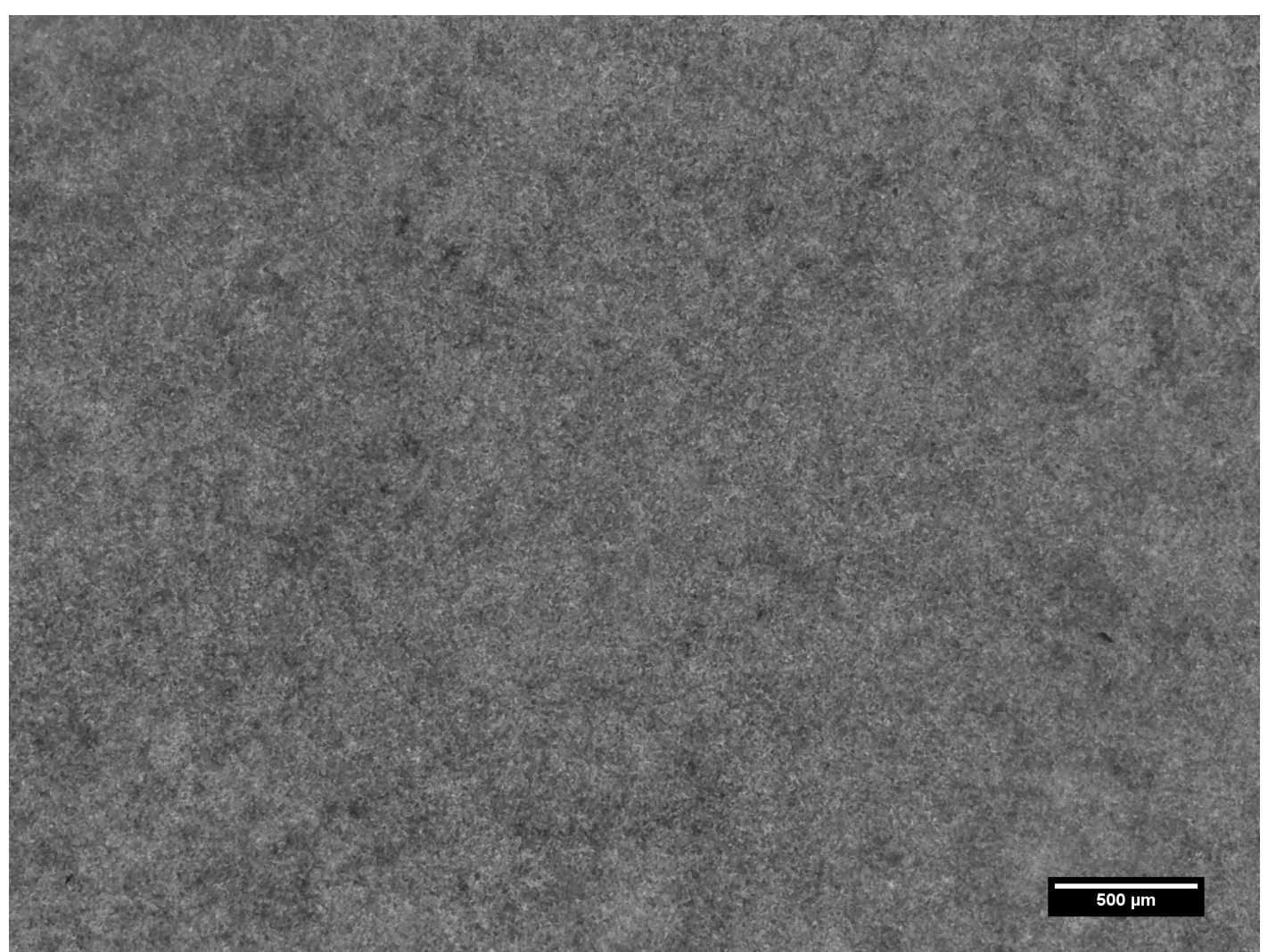

Example of neuronal culture at Day 11 of differentiation 


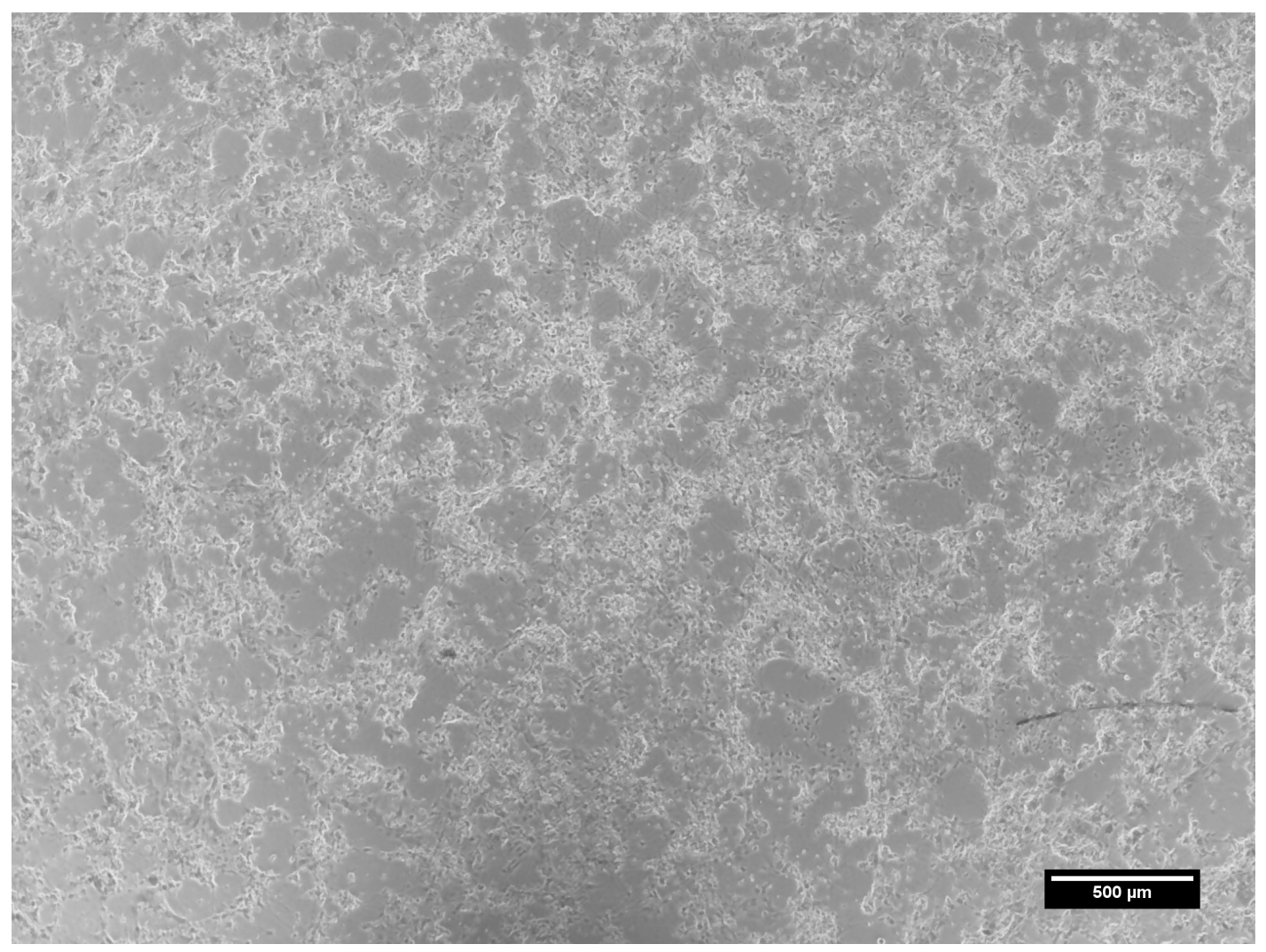

Example of neuronal culture at Day $\mathbf{3 0}$ of differentiation 


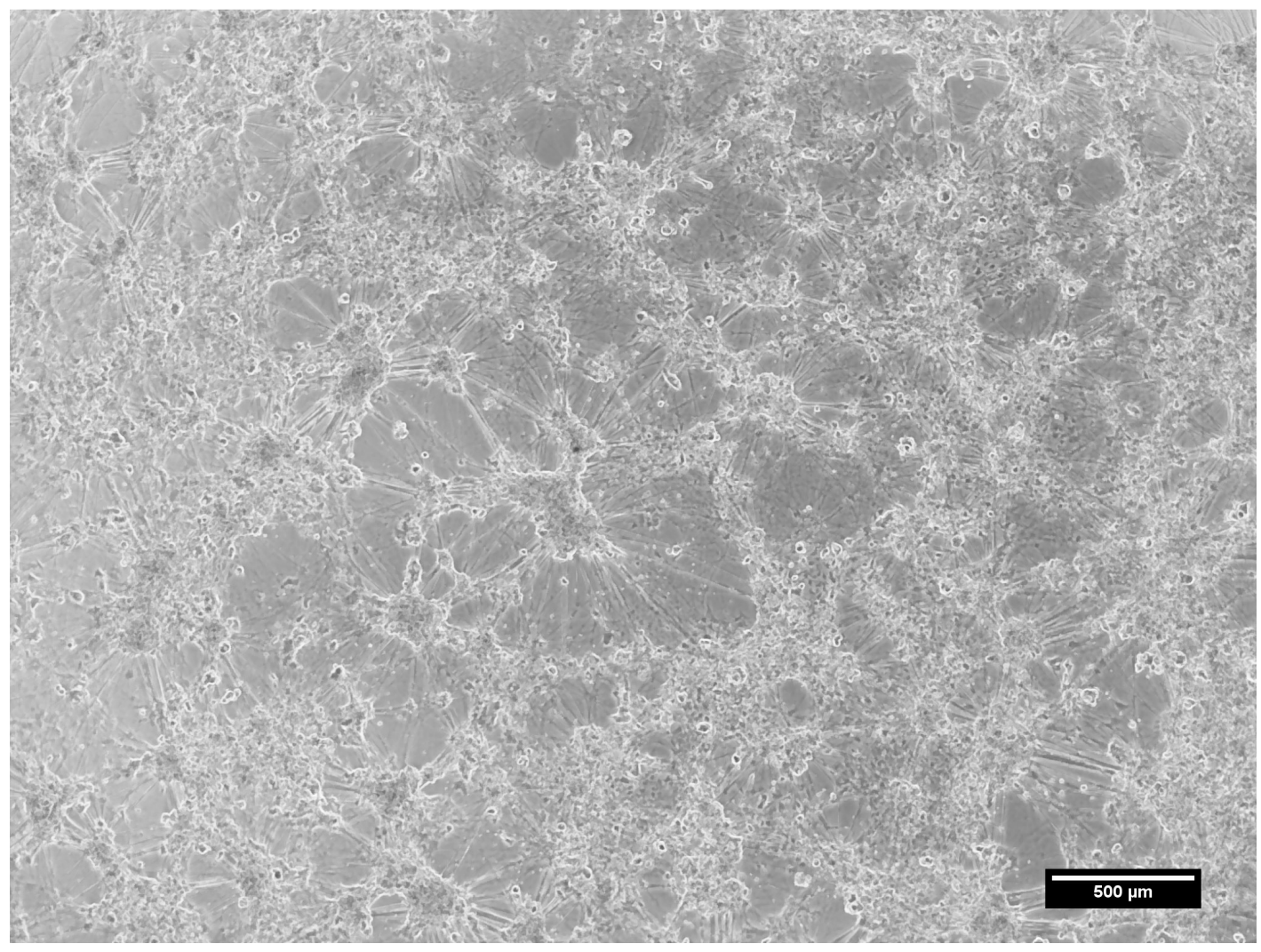

Example of neuronal culture at Day $\mathbf{5 2}$ of differentiation 
MATERIALS

MATERIALS

88 Ice Contributed by users

88 DNA LoBind Tubes, $1.5 \mathrm{~mL}$ Eppendorf Catalog \#0030108051

88 DPBS Invitrogen - Thermo Fisher Catalog \#14190

88

Falcon $^{\text {TM }} 15 \mathrm{~mL}$ Conical Centrifuge Tubes Fisher Scientific Catalog \#14-95953A

88 DMEM/F-12, GlutaMAX ${ }^{\mathrm{TM}}$ supplement Thermo Fisher Catalog \#10565018

8 StemPro $^{\mathrm{TM}}$ Accutase $^{\mathrm{TM}}$ Cell Dissociation Reagent Thermo Fisher Catalog

88 \#A1110501

88 Y-27632 dihydrochloride Sigma - Aldrich Catalog \#Y0503

88 DNase Vial (D2) Worthington Biochemical Corporation Catalog \#LK00317

8 PDS Kit Papain Vial Worthington Biochemical Corporation Catalog \#LK003176

88 PluriStrainer Mini 40 $\mu \mathrm{m}$ pluriSelect Catalog \#43-10040-60

$881.5 \mathrm{ml}$ TubeOne® Microcentrifuge Tubes Natural (Sterile) StarLab Catalog \#S1615-5510

88 Bovine Serum Albumin Sigma Catalog \#A0281

88 Water for embryo transfer sterile filtered Sigma Aldrich Catalog \#W1503$500 \mathrm{ML}$

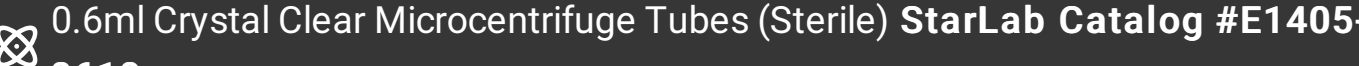
0610

12-well Falcon ${ }^{\text {TM }}$ Polystyrene Microplates Fisher Scientific Catalog \#10489482

\section{Equipment:}

Centrifuge (for both $15 \mathrm{~mL} \& 1.5 \mathrm{~mL}$ tubes)

Pipette boy

Sterile $5 / 10 \mathrm{~mL}$ stripettes

P1000 pipette and filter tips

Vacuum aspirator and tips

Microbiology Safety Cabinet (MSC)

Light Microscope

Scale (for making up BSA)

Method of Cell Counting (NucleoCounter ${ }^{\circledR} \mathrm{NC}-200^{\text {TM }}$ )

$8^{\circ} 37^{\circ} \mathrm{C}, 5 \% \mathrm{CO}_{2}$ incubator 
(4) Rock inhibitor (Y-27632) - Harmful if swallowed, in contact with skin or inhaled.

\section{BEFORE START INSTRUCTIONS}

Prepare a $10 \%$ BSA solution [M] $100 \mathrm{mg} / \mathrm{mL}$ by dissolving Bovine Serum Albumin powder in sterile Water for Embryo Transfer (or equivalent water for cell culture). Filter sterilise with a $\rightarrow+-0.2 \mu \mathrm{m}$ sterilising grade filter. Aliquot into sterile $0.6 \mathrm{~mL}$ microcentrifuge tubes. Store at $\mathfrak{8}^{\circ}-20^{\circ} \mathrm{C}$. Thaw at $\AA^{\circ}$ Room temperature and resuspend prior to use.

- Pre-warm Accutase to $88^{\circ} 37^{\circ} \mathrm{C}$ shortly before starting (Caution: Accutase is inactivated after 45 minutes at $88^{\circ} 37^{\circ} \mathrm{C}$ )

- If working with mature neurons, calculate how many vials of Papain/DNase you will need given the number of wells being harvested.

\section{Buffer Preparation}

Prepare Wash Buffer 1 (without DNase) by supplementing 15mL DMEM:F12 + GlutaMAX with ROCK inhibitor (Y-27632) to a final concentration of $10 \mu \mathrm{M}$.

Note: We make up $15 \mathrm{~mL}$ of Wash Buffer 1 for every 6 wells of a 12 well plate to dissociate.

For mature neurons, 1 vial DNase (D2) should be added for every $15 \mathrm{~mL}$ of buffer prepared. However, DNase should only added immediately prior to use of the buffer when the cells are nearing the end of their dissociation. Keep the DNase at $8^{\circ} 4^{\circ} \mathrm{C}$ until use.

\begin{tabular}{|c|c|c|c|}
\hline Cells & $\begin{array}{l}\text { DMEM/F12 + } \\
\text { glutamax }\end{array}$ & $\begin{array}{l}\text { Rock inhibitor (Y- } \\
27632) 10 \mathrm{mM} \text { stock }\end{array}$ & DNase (D2) \\
\hline $\begin{array}{l}\text { Neuronal progenitors ( Day } \\
11 \text { ) }\end{array}$ & $15 \mathrm{~mL}$ & $15 \mathrm{uL}$ & Not required \\
\hline Mature Neurons (> Day 20) & $15 \mathrm{~mL}$ & $15 \mathrm{uL}$ & 1 vial (250uL) \\
\hline
\end{tabular}

Wash Buffer 1 composition for cells at different stages

2 Prepare Wash Buffer 2 by adding 10\% BSA solution (100 $\mu \mathrm{g} / \mathrm{mL})$ to DPBS (-/-) to a final concentration of $400 \mu \mathrm{g} / \mathrm{mL}$. i.e. add $60 \mu \mathrm{L} 10 \%$ BSA solution to $15 \mathrm{~mL}$ of DPBS (-/-). 
3 Prepare Dissociation Buffer for mature neurons by combining Accutase with DPBS (-/-) at a 1:1 ratio. Add 1 vial Papain (PDS Kit) per $5 \mathrm{~mL}$ buffer. Reconstitute the lyophilised papain with the Accutase/DPBS solution, replace the lid on the vial and invert several times ensuring all powder in the vial and on the lid is dissolved. Transfer solution back into the Dissociation Buffer tube.

Dissociation Buffer for neuronal progenitors is undiluted Accutase only.

\begin{tabular}{|l|l|l|l|}
\hline Cells & Accutase & DPBS (-/-) & $\begin{array}{l}\text { Papai } \\
\text { n } \\
\text { (PDS } \\
\text { kit) }\end{array}$ \\
\hline $\begin{array}{l}\text { Neuronal progenitors ( Day } \\
11)\end{array}$ & $0.5 \mathrm{~mL}$ per well & Not required & $\begin{array}{l}\text { Not } \\
\text { requir } \\
\text { ed }\end{array}$ \\
\hline Mature Neurons (> Day 20$)$ & $2.5 \mathrm{~mL}$ & $2.5 \mathrm{~mL}$ & 1 vial \\
\hline
\end{tabular}

Dissociation Buffer composition for cells at different stages

\section{Dissociation}

4 Aspirate the media from the well(s) of the neuronal culture and gently add $\triangle 1 \mathrm{~mL}$ of DPBS (-/-) without disturbing the cell layer.

5 Aspirate the DPBS (-/-) and add $\triangle 0.5 \mathrm{~mL}$ of Dissociation Buffer to each well.

6 Transfer cells to a $8^{\circ} 37^{\circ} \mathrm{C} \quad 5 \% \mathrm{CO}_{2}$ tissue culture incubator. Incubate for the appropriate time according to age of the culture:

- Early neuronal progenitors ( Day 11) - 00:10:00 (up to 20 mins)

- Young mature neurons ( Day 30) - 00:20:00 (up to 30 mins)

- Older mature neurons ( Day 52) - 00:25:00 (up to 35 mins)

Check the progress of the dissociation after the indicated time. If necessary extend the 
incubation period for up to 10 mins more, checking the cells every few minutes.

7 For dissociation of mature neurons complete the preparation of Wash Buffer 1 within the last 5 minutes of incubation of the cells.

- Retrieve the DNase (D2) vial(s) from $8^{\circ} 4^{\circ} \mathrm{C}$ storage.

- Reconstitute the vial(s) by adding $250 \mu \mathrm{L}$ Wash Buffer 1 to each vial to make a $2 \mathrm{mg} / \mathrm{mL}$ solution. Make sure to reconstitute all the powder (check the lid). Avoid vigorous mixing - do not vortex.

- Transfer the entire contents of the reconstituted vial(s) back into the Wash Buffer 1 tube. Use $250 \mu \mathrm{L}$ (1 vial) for every $15 \mathrm{~mL}$ buffer.

8 Following incubation inspect the cells under a microscope.

The cells should be detaching from the plate and the cell layer should have a darkened appearance. Cells will have a rounded appearance as they dissociate and individual cells should be visible at the edges or in gaps in the cell layer.

9 Optional: Test for ease of dissociation by gently pipetting $\triangle 100 \mu \mathrm{L}$ of the Dissociation Buffer against the cells with a P1000 pipette. If cells do not dissociate easily, extend digestion by 00:03:00 and repeat this step.

10 Add $\triangle 2 \mathrm{~mL}$ of Wash Buffer 1 per well.

11 Use a P1000 pipette to repeatedly wash the buffer over the well(s) to detach the cells and dissociate them to a single-cell suspension.

Sufficient dissociation is critical at this step. It is recommended to check the cell suspension under a microscope and if necessary pipette the cell suspension up and down further until the majority is single cells. Try to avoid over-pipetting the cells as this could affect viability.

12 Transfer the cell suspension into a $15 \mathrm{~mL}$ centrifuge tube capped with a $40 \mu \mathrm{m}$ cell strainer. 
13 Optional: If there are residual cells in the plate, wash well(s) with $\Delta 0.5 \mathrm{~mL}$ of Wash Buffer 1 and transfer this suspension into the tube from the previous step.

14 Centrifuge cells at $\because 150 \times \mathrm{g}$, Room temperature, 00:03:00

15 Aspirate supernatant and gently re-suspend the cell pellet in $\triangle 1 \mathrm{~mL}$ of Wash Buffer 2 with a P1000 pipette.

16 Transfer the cells to a Lo-bind 1.5mL Eppendorf tube.

We recommend preparing and thawing necessary reagents for the 10x loading procedure during these next steps if you have not already done so.

17 Repeat steps 14 \& 15 three times in a mini centrifuge (for a total of four centrifugations).

\section{Cell Counts}

18 Note: This step describes a 1 in 10 dilution for cell counting on a NucleoCounter ${ }^{\circledR} \mathrm{NC}-200^{\text {Tm. }}$. Depending on method of cell counting and number of cells, this dilution step may not be necessary.

Prepare a cell count sample tube for each suspension prepared by adding $\pi 450 \mu \mathrm{L}$ of Wash

Buffer 2 to a fresh Lo-bind 1.5ml Eppendorf tube.

Take a $\triangle 50 \mu \mathrm{L}$ aliquot of the well-mixed cell suspension and add this to the $\triangle 450 \mu \mathrm{L}$ of Wash Buffer 2 in the prepared counting tube(s).

19 Place the cell suspension tube(s) $\AA^{\circ}$ On ice during the cell counts and following steps. 
20 Count the cell suspension(s) on a NucleoCounter ${ }^{\circledR} \mathrm{NC}-200^{\mathrm{Tm}}$ and record \% cell viability and viable cell concentration. Ensure less than $3 \%$ of cells are in aggregates.

If $>3 \%$ of the cells are in aggregates, triturate the cell suspension by pipetting up and down with a P1000 pipette. Carry out a second cell count on a new sample. Alternatively, dilute the sample and pass through a cell strainer, then centrifuge and resuspend in $1 \mathrm{~mL}$ Wash Buffer 2 before repeating the cell count.

21 Using the cell counts, calculate the dilution of the cell suspension(s) necessary to produce the desired cell number for loading for the 10x. Dilutions should be made using Wash Buffer 2, to a final volume of $\triangle 1 \mathrm{~mL}$

22 Keeping the cell suspensions $8^{\circ}$ On ice proceed with the sample preparation and loading steps described in the 10x Genomics single cell gene expression kit guidelines.

23 We recommend performing a post-10x loading cell count on the diluted cell suspension. This cell count can normally be performed without further dilution (depending on the method of cell counting). This cell count will confirm the cell number loaded for $10 x$ and check the cell viability has not dropped significantly since the first cell count. It can also check the percentage cell aggregates has remained acceptable. 